\title{
Development of Ultra-Low Friction Coefficient Films and Their Effect on the Biocompatibility of Biomedical Steel
}

\author{
Alexis Chino-Ulloa ${ }^{1}$, Mario Hernandes-Alejandro ${ }^{1}$, José L. Castrejón-Flores ${ }^{2}$, Moisés Cabrera-González ${ }^{3}$, \\ Itzel P. Torres-Avila ${ }^{1}$, Julio C. Velázquez ${ }^{4}$, Pablo A. Ruiz-Trabolsi ${ }^{1}$ and Enrique Hernández-Sánchez ${ }^{1, *}$ \\ ${ }^{1}$ Instituto Politécnico Nacional-UPIBI, Departamento de Bioingeniería, Avenida Acueducto s/n Barrio La Laguna Ticomán, \\ 07340, México City, México \\ ${ }^{2}$ Instituto Politécnico Nacional-UPIBI, Departamento de Bioprocesos, Avenida Acueducto s/n Barrio La Laguna Ticomán, \\ 07340, México City, México \\ ${ }^{3}$ Departamento de Infectómica y Patogénesis Molecular, CINVESTAV-IPN, Av. Instituto Politécnico Nacional 2508, col San Pedro \\ Zacatenco, México City 07360 México \\ ${ }^{4}$ Departamento de Ingeniería Química Industrial, ESIQIE, Instituto Politécnico Nacional, UPALM Edif. 7 , \\ Zacatenco, México City 07738, México
}

\begin{abstract}
This study evaluates the effect of a self-lubricant film with ultra-low friction coefficient on the biocompatibility of the AISI 316L. The samples were thermochemically treated to generate a hard surface layer of iron borides followed by a secondary process. The purpose of the secondary process was to generate a self-lubricant film of boric acid. The ultra-low friction coefficient of boric acid films was estimated in 0.02 compared to 0.2 and 0.8 for borided and as-received AISI 316L steel respectively. The effect of the boric acid films on the steel's biocompatibility was evaluated by the culture of Madin-Darby canine kidney II (MDCK II) cells with exposure times of $0,4,8,12,24,48$ and $72 \mathrm{~h}$. The In vitro tests revealed the absence of cytotoxic effect by the direct exposure of the cells to the samples. Additionally, the presence of signs early apoptosis by the determination of the expression of the cysteinyl proteases termed caspase- 3 and -9 was determined. Their presence was assessed by indirect immunofluorescence in cells in direct contact with the samples. No significant expression of the proteolytic enzymes was detected. All these results suggest that the surface film of boric acid does not induce any cytotoxic effect and does not inhibit the cell-cell adhesion. [doi:10.2320/matertrans.M2019035]
\end{abstract}

(Received January 31, 2019; Accepted April 16, 2019; Published May 31, 2019)

Keywords: ultra-low friction coefficient, boric acid, solid lubricant, biocompatibility, cytotoxicity

\section{Introduction}

In recent years, many strategies have been implemented for replacing metallic materials used in orthopedic surgery. Particularly, in the development of better materials which can interact with living tissue without causing damage and without being affected by it. ${ }^{1)}$ Ceramic materials such as alumina $\left(\mathrm{Al}_{3} \mathrm{O}_{3}\right)$ and Partially Stabilized Zirconia (PSZ) $\left(\mathrm{ZrO}_{2}\right)$, as well as Ultra High Molecular Weight Polyethylene (UHMWPE), have been used alone or in combination with biocompatible metals. The main reason for the replacement of the metals used in the manufacturing of joint prostheses is the deterioration which experiments all of them due to the high salts concentration in the body fluids. ${ }^{2)}$ Nevertheless, the total substitution of metals as replacement materials has not yet been possible due to its characteristic mechanical properties, particularly their impact resistance and tensile strength. Furthermore, some authors have reported that polyethylene particles detached to the body because of the friction of the joint prostheses in the metal-polyethylene tribological pair, generate more damage to the surrounding tissues than that caused by the release of metal particles from the metal-metal tribological pairs. ${ }^{3,4)}$ Wear is an inherent phenomenon which occurs as a consequence of friction at the surface of the materials in practically every equipment with elements in contact with relative movement causing loss of material. In that sense, several investigations aimed into modifying the surface of materials not only to increase its

*Corresponding author, E-mail: enriquehs266@yahoo.com.mx wear resistance but also their resistance to the corrosion caused by direct contact with biological fluids. ${ }^{2,5)}$ Surface treatments including nitriding, carburizing and boriding, have been successfully applied for the improvement of the surface properties of metallic materials enhancing their mechanical, chemical and physical properties. ${ }^{6}$ ) Unfortunately, these treatments have not had a positive impact on the coefficient of friction $(\mathrm{CoF})$ and the durability of the material once implanted. ${ }^{7}$

Therefore, the development of materials with the capability to reduce friction between them result of great interest. Solid lubricants including molybdenum disulfide, graphite, hexagonal boron nitride, and boric acid have been investigated as a solution due to their capacity to reduce friction. ${ }^{8-10)}$ Erdemir et al. have developed a process to generate a boric acid film $\left(\mathrm{H}_{3} \mathrm{BO}_{3}\right)$ at the surface of boron-rich materials. ${ }^{11,12)}$ This $\mathrm{H}_{3} \mathrm{BO}_{3}$ film acts as a solid lubricant because its lamellar crystalline structure, where the atomic layers align themselves in the sliding interface and parallel to the direction of relative movement sliding one over another easily decreasing the friction and consequently wear. ${ }^{13)}$ In previous work by our research group, it was demonstrated that by controlling the relative humidity $(\mathrm{RH})$ during the cooling phase, it is possible to favor the formation of $\mathrm{H}_{3} \mathrm{BO}_{3}$ films with a higher self-lubricant capability. ${ }^{14)}$ Although, the effect in living tissues of these films has not been addressed before. In addition, many biomedical materials may contain one or more extractable substances that could be of clinical importance. Testing for cytotoxicity is indispensable towards ensuring the biocompatibility of a medical device for 
biomedical applications. Cytotoxicity tests, like 3-(4,5-dimethylthiazol-2-yl)-2,5-diphenyltetrazolium bromide (MTT) colorimetric assay reveal the biocompatibility of nickel, $\mathrm{Fe}_{3} \mathrm{O}_{4}$ and many other nanoparticles in micromolar concentrations on human glia, human breast cancer, and normal cell lines. ${ }^{15-18)}$

Thus, the aim of our investigation is to generate boride and $\mathrm{H}_{3} \mathrm{BO}_{3}$ films at the surface of biomedical grade steel to reduce its $\mathrm{CoF}$ and to evaluate their biocompatibility.

The steel samples were previously surface hardened by means of boron diffusion by a process known as boriding. ${ }^{19)}$ As a result of boriding, hard layers with high mechanical, physical and chemical properties are expected. ${ }^{19-21)}$ The boride layers generated on the ferrous alloys, could be $\mathrm{Fe}_{2} \mathrm{~B}$ and/or $\mathrm{FeB} / \mathrm{Fe}_{2} \mathrm{~B}$ type. Boron concentration at the $\mathrm{Fe}_{2} \mathrm{~B}$ phase is $8.7 \%$ mass, while in the $\mathrm{FeB}$ phase is $16.3 \%$ mass. So, it is possible to assume that the FeB phase is more apt to promote the formation of $\mathrm{H}_{3} \mathrm{BO}_{3}$ films because of its higher content of boron. ${ }^{19)}$

The MTT is a commonly used assay to evaluate the cytotoxic effect of the layers formed in a biological environment due to its sensitive detecting loss of viability and high reproducibility. ${ }^{22,23)}$ On the other hand, the immunofluorescence assay is used as a more complex test to corroborate the results of the MTT assay, cytotoxicity is quantified by means of the light intensity emitted by the cells and the antibodies that interact with them.

By comparing the cytotoxicity in vitro, measured by the MTT assays and caspases expression, in both, non-borided, borided and borided and annealed AISI 316L steel samples, it was demonstrated that the treated materials did not cause cells death nor indicate early signs of mitochondrial damage. Thus, the presence of the $\mathrm{H}_{3} \mathrm{BO}_{3}$ film with self-lubricating capacities might be a safe alternative for the development of wear resistant materials for biomedical applications.

\section{Experimental Details}

\subsection{Boriding treatment}

Cylindrical samples of AISI 316L steel with a chemical composition as shown in Table 1, were cut into a size of $12.7 \mathrm{~mm}$ in diameter and $5.0 \mathrm{~mm}$ in thickness. The surfaces of the samples were prepared by a traditional metallographic procedure using $\mathrm{SiC}$ abrasive paper until 1000 mesh.

The samples were cleaned in an ultrasonic bath during $5 \mathrm{~min}$ in ethanol and dried in hot air and then embedded in boron powder source with a grain size of $50 \mu \mathrm{m}$. The boriding treatment was carried out at a constant temperature of $950^{\circ} \mathrm{C}$ during $6 \mathrm{~h}$ in order to generate a compact and homogenous layer of iron borides. ${ }^{5,14)}$ After boriding, samples were cooled inside the furnace until room temperature.

In order to facilitate the handle and control of samples, they were numbered as shown in Table 2 .

\subsection{Layer characterization}

The presence of the borided layers was observed by means of optical microscopy (OM) with the aid of an Olympus GX51 optical microscope and scanning electron microscopy (SEM) (JOEL, JSM-7401). Before the OM and SEM examination, one sample on each treatment condition was
Table 1 Chemical composition of the AISI 316L steel.

\begin{tabular}{cc}
\hline Element & Weight $(\%)$ \\
\hline $\mathrm{C}$ & 0.03 \\
$\mathrm{Si}$ & $1.0 \mathrm{max}$. \\
$\mathrm{Mn}$ & $2.0 \mathrm{max}$ \\
$\mathrm{Cr}$ & $16.7-18.0$ \\
$\mathrm{Ni}$ & $10.0-14.0$ \\
$\mathrm{Mo}$ & $2.0-3.0$ \\
$\mathrm{P}$ & $0.045 \mathrm{max}$ \\
$\mathrm{S}$ & 0.03 max \\
$\mathrm{Fe}$ & Balance \\
\hline
\end{tabular}

Table 2 Nomenclature for the different samples condition.

\begin{tabular}{cc}
\hline Sample condition & Nomenclature \\
\hline Non-borided & M1 \\
Borided & M2 \\
Borided-annealed & M3 \\
\hline
\end{tabular}

cross-sectioned and prepared by a conventional metallographic procedure. The nature of the layers was corroborated by the X-Ray Diffraction technic (XRD), using a Bruker D8 FOCUS diffractometer equipped with $\mathrm{CuK}_{\alpha}$ radiation at $\lambda=$ $1.54 \AA$. The XRD examination was realized on the surface of the samples.

The hardness and Young's modulus of the layers were evaluated by the instrumented indentation technique with the aid of a nanohardness tester (TTX-NHT, CSM Instruments), using a Berkovich indenter and following the methodology established by Oliver and Pharr. ${ }^{24)}$ According to the Oliver and Pharr method, in nanoindentation, the depth of penetration of a diamond indenter is measured along with the established load. The resulting load-displacement response typically shows an elastic-plastic loading followed by elastic unloading. The elastic equations of contact are then used in conjunction with the unloading data to determine Young's modulus and hardness of the specimen material as follow:

$$
\begin{aligned}
& H=P / A_{c} \\
& E=\left(1-v_{s}^{2}\right) /\left[\left(1 / E_{r}\right)-\left(\left(1-v_{i}^{2}\right) / E_{i}\right)\right] \\
& E_{r}=\sqrt{\pi S / 2 \beta \sqrt{A_{c}\left(h_{c}\right)}}
\end{aligned}
$$

where $H$ is the hardness of the specimen, $P$ is the applied load, $A_{c}$ is the contact area at peak load $\left(24.49 h_{c}^{2}\right), h_{c}$ is the experimentally measured contact indentation depth, 24.49 is a constant related with the geometry of the indenter, $E$ is the Young's modulus, $\vartheta_{s}$ is the Poisson's ratio of the sample (0.3), $\vartheta_{i}$ is Poisson's ratio of the indenter $(0.07), E_{i}$ is Young's modulus of the indenter $(1141 \mathrm{GPa}), E_{r}$ is a reduced modulus 


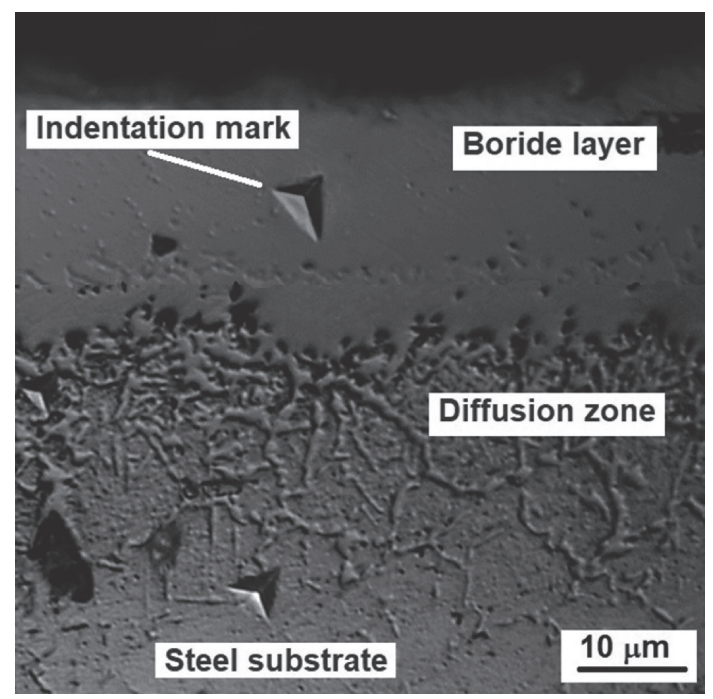

Fig. 1 Indentation marks on the boride layer obtained at $950^{\circ} \mathrm{C}$, during $6 \mathrm{~h}$ of treatment.

of the indentation contact, and $S$ is the stiffness of the sample. The contact depth $h_{c}$ values are supplied by the nanoindenter since it is an instrumented equipment.

A set of indentations was realized at different distances from the surface of the layer to evaluate the influence of the boron concentration on the mechanical properties of the boride layers. At least ten indentations were realized in each distance in order to ensure the reproducibility of the results (see Fig. 1). The distance between indentation prints was established by following the limits of the ISO instrumented indentation standards (ISO 14577-1-2002) in order to avoid the interaction between the stresses field of the indentations. ${ }^{25)}$ The indentation load was established in $250 \mathrm{mN}$ considering the thickness of the layers.

\subsection{Short annealing process (SAP)}

SAP was performed in a conventional furnace at $750^{\circ} \mathrm{C}$ for 5 minutes in open air. ${ }^{11)}$ Then, samples were cooled until room temperature in a controlled moisture chamber. The Relative Humidity $(\mathrm{RH})$ during the cooling process was established in $60 \%$ to achieve the best results of the CoF as was established in a previous investigation. ${ }^{14)}$ The presence of the $\mathrm{H}_{3} \mathrm{BO}_{3}$ was corroborated by $\mathrm{OM}$ and SEM. Also, Raman spectroscopy was applied to the annealed samples in order to establish the nature of the $\mathrm{H}_{3} \mathrm{BO}_{3}$ films.

\subsection{Coefficient of friction (CoF) tests}

The self-lubricant nature of the $\mathrm{H}_{3} \mathrm{BO}_{3}$ films was established by evaluating their $\mathrm{CoF}$ with the aid of a pinon-disk tribometer. The tests were performed at a controlled temperature of $19^{\circ} \mathrm{C}$ with $40 \%$ of $\mathrm{RH}$ and a constant rotational speed of $10 \mathrm{rpm}$. The sliding speed was held constant at $0.05 \mathrm{~m} \mathrm{~s}^{-1}$ for a sliding distance of $100 \mathrm{~m}$ and the normal load applied on the wear tungsten carbide (WC) ball was $5 \mathrm{~N}$. Five tests were realized under the same condition for reproducibility of the results.

\subsection{In vitro cellular test}

During the in vitro assays, the MDCK II cell line was incubated in direct contact with M1, M2, and M3 samples.
First, the samples were placed into an empty well of 12 well culture plate, then culture medium was added until the samples were totally covered $(1.5 \mathrm{ml})$ and finally the cell line was added to incubate during different periods of time according to the ISO $10993-5 .^{26}$ )

\subsubsection{Samples treatment}

Before the in vitro cellular tests, samples in all conditions (see Table 2) were carefully polished with alumina of 0.05 microns to eliminate the excess of $\mathrm{H}_{3} \mathrm{BO}_{3}$ crystals. Then, the samples were cleaned in an ultrasonic bath for $5 \mathrm{~min}$ in benzalkonium chloride $1 \%$ and dried in hot air. Samples were then sterilized by steam for $2 \mathrm{~h}$.

\subsubsection{Tissue-cultured monolayers}

In vitro cultures of MDCK II cell line (Madin-Darby canine kidney II) was used to analyze the biocompatibility of the three conditions of steel samples: M1, M2, and M3. Monolayers of MDCK II cultured cells (initial cell seeding density $1.5 \times 10^{3}$ cells/well) were grown in 96-well tissue culture plates (Corning Inc., NY, USA) and maintained in Dulbecco's Modified Eagle's Medium (containing 10\% fetal calf serum, $4 \mathrm{mM}$ L-glutamine, 10 units $/ \mathrm{ml}$ penicillin, and $10 \mathrm{mg} / \mathrm{ml}$ streptomycin) at $37^{\circ} \mathrm{C}$ in a $5 \% \quad \mathrm{CO}_{2}$ moist atmosphere for $24-48 \mathrm{~h}$.

\subsubsection{Cell-cytotoxicity and methyl thiazolyl tetrazolium} (MTT) assay

To determine the cellular viability, the MDCK II cells were incubated with the samples in all conditions (M1, M2, and M3), during 0, 4, 8, 12, 24, 48 and $72 \mathrm{~h}$. Samples were removed and the mitochondrial function of the exposed cells was assessed by the MTT assay. Briefly, $50 \mu \mathrm{L}$ of the MTT [3-(4,5-dimethylthiazol-2-yl)-2,5-diphenyltetrazolium bromide] reagent $(5 \mathrm{mg} / \mathrm{mL})$ was added and incubated for another $4 \mathrm{~h}$ at $37^{\circ} \mathrm{C}$. Then, $500 \mu \mathrm{L}$ of DMSO were added and homogenized for $10 \mathrm{~min}$. The supernatant was recovered $(100 \mu \mathrm{L})$ and was evaluated by detection of absorbance at $490 \mathrm{~nm}$ using a Synergy plate reader (Bio-Tek Instruments). Results were reported as the means \pm standard deviation of three independent experiments by triplicate.

\subsubsection{Immunofluorescence assay protocol}

MDCK II monolayers $\left(1 \times 10^{4}\right.$ cells $)$ were grown on coverslips in 12-well plates (Costar) and were incubated with samples (M1, M2, and M3) during 4, 8, 12 and $24 \mathrm{~h}$ at $37^{\circ} \mathrm{C}$. Samples and supernatants were removed. Thereafter, a permeabilizing/blocking solution containing PBS with $1 \%$ Bovine serum albumin (BSA) and $0.2 \%$ Triton X-100 was added for a $5 \mathrm{~min}$ incubation. After $24 \mathrm{~h}$ of incubation with primary antibodies caspase 3 and caspase 9 in $0.01 \%$ PBSTriton, a Cy3 or FITC conjugated secondary antibodies diluted in PBS-triton were added and incubated for $2 \mathrm{~h}$ at $37^{\circ} \mathrm{C}$. Fluorescent samples were analyzed in an epifluorescence microscope (Carl Zeiss, Inc., Jena, Germany).

\section{Results and Discussions}

\subsection{Microstructure}

Figure 2 shows an OM and SEM view of the cross-section of the AISI 316L borided steel, where it is possible to observe a well-defined layer of borides with flat morphology which is expected when stainless steel is exposed to boriding treatment. 

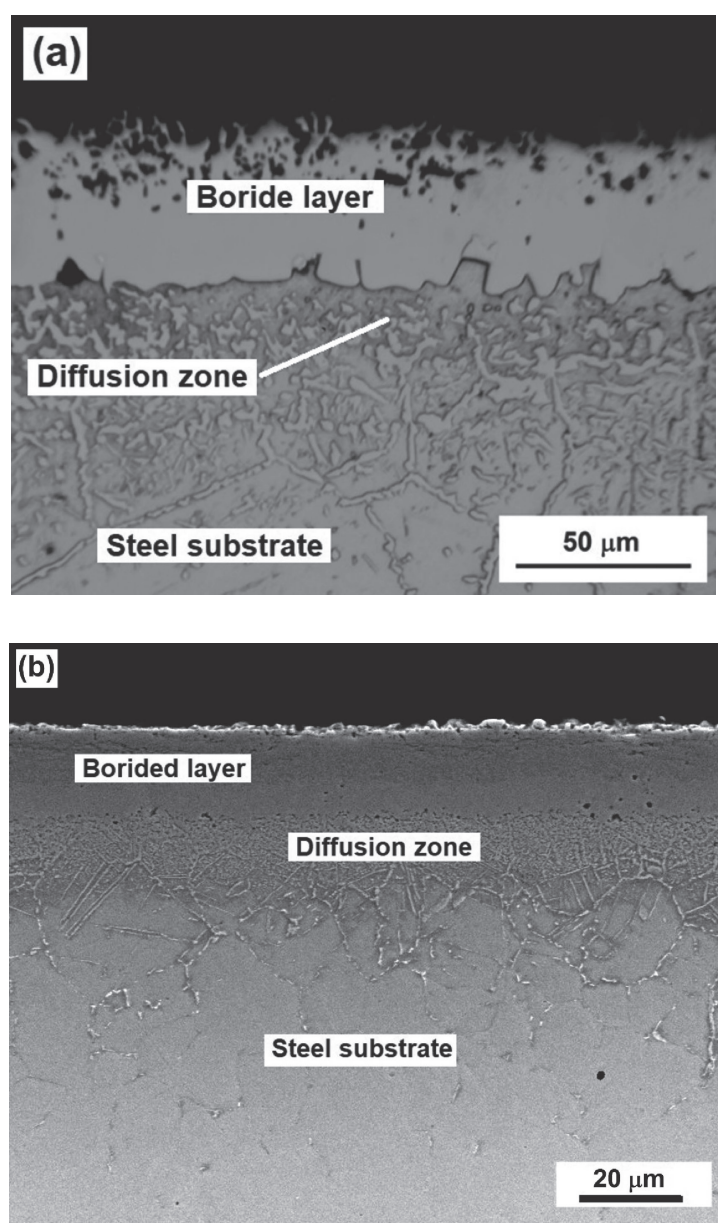

Fig. 2 Cross section of AISI 316L borided steel (a) optical microscopy and (b) SEM image, the microstructure was revealed with Vilella's reagent ( $1 \mathrm{~g}$ picric acid, $5 \mathrm{ml} \mathrm{HCl}, 100 \mathrm{ml}$ ethanol).
The flat morphology of the layers can be attributed to the high concentration of alloying elements in the substrate ${ }^{5)}$ Palombarini and Carbucicchio in their work "On the morphology of thermochemically produced $\mathrm{FeB} / \mathrm{Fe}$ interfaces", ${ }^{27)}$ presented an explanation for this behavior. They encountered that high content of alloying elements, especially $\mathrm{Ni}$ and $\mathrm{Cr}$ are responsible not only for the flat morphology of the boride layers but also for the reduction on the thickness of the boride layers. During the boriding process, alloying elements tend to concentrate at the tips of the boride columns by a substitutional procedure, so, as the AISI 316L has a high content of alloying elements such as $\mathrm{Cr}$ and $\mathrm{Ni}$ (see Table 1), much of the activation energy is lost and the active boron flux in these zones decrease. This sequence of events inhibits the growth of the layers and the columnar growth in alloyed steels compared to those obtained when low alloying steels are exposed to boriding. ${ }^{28)}$

It is possible to observe three different zones in the crosssectioned borided samples (Fig. 2). The outermost seems to be a layer containing mainly borides $\left(\mathrm{FeB}, \mathrm{Fe}_{2} \mathrm{~B}, \mathrm{CrB}\right.$, $\left.\mathrm{Ni}_{3} \mathrm{~B}\right),{ }^{14}$ ) a second zone which is the region below boride layers which is called diffusion zone and the steel substrate, which is not affected by boron diffusion.

The XRD analysis corroborated the nature of the surface layers (Fig. 3).

In the XRD pattern (Fig. 3(a)), it is possible to observe strong picks indicating the presence of $\mathrm{FeB}$ and $\mathrm{Fe}_{2} \mathrm{~B}$ phases and also small traces of $\mathrm{Cr}_{2} \mathrm{~B}$ and $\mathrm{Ni}_{3} \mathrm{~B}$ can be observed. Likewise, the phases distribution graphic (Fig. 3(b)) shows the content of each phase present at the surface of the borided samples. According to Fig. 3(b), the FeB phase represents more than $50 \%$ of the boride layer, which could optimize the generation of the $\mathrm{H}_{3} \mathrm{BO}_{3}$ film on the surface of the borided
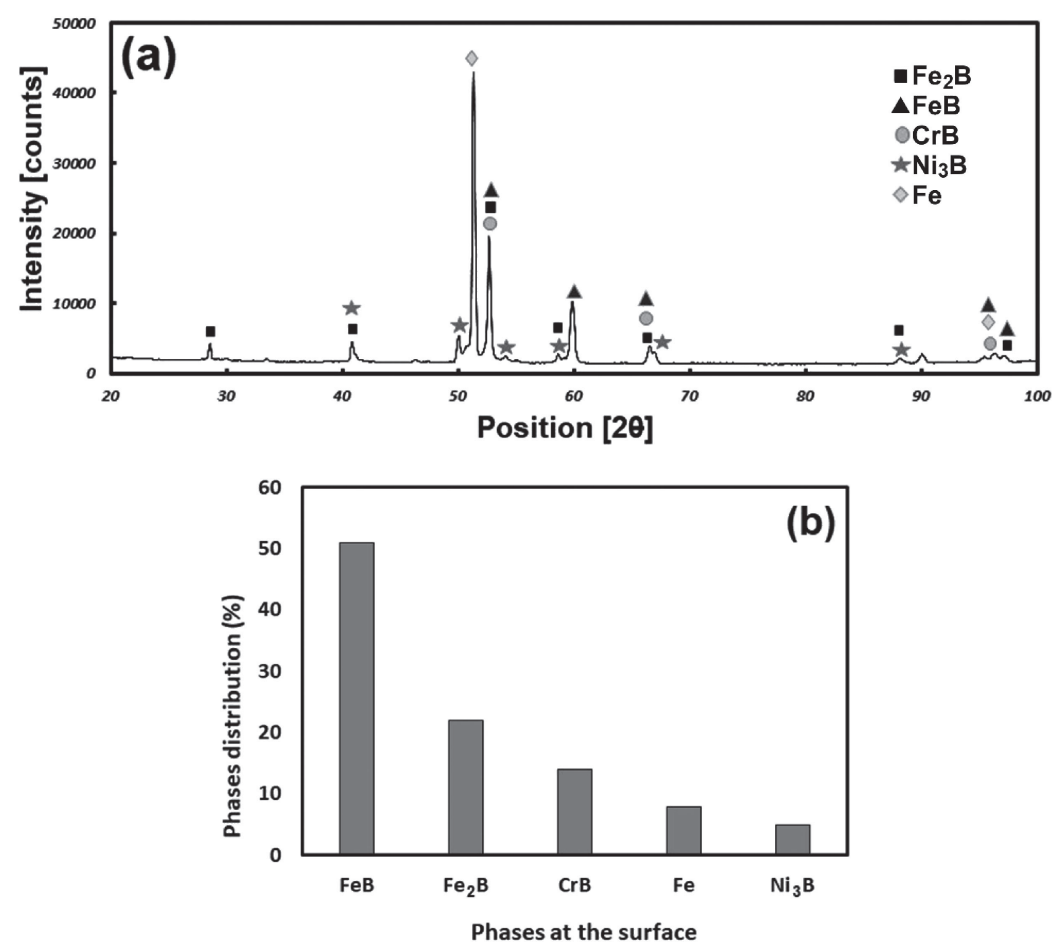

Fig. 3 (a) XRD pattern and (b) phases distribution on the surface of the AISI 316L borided steel. 

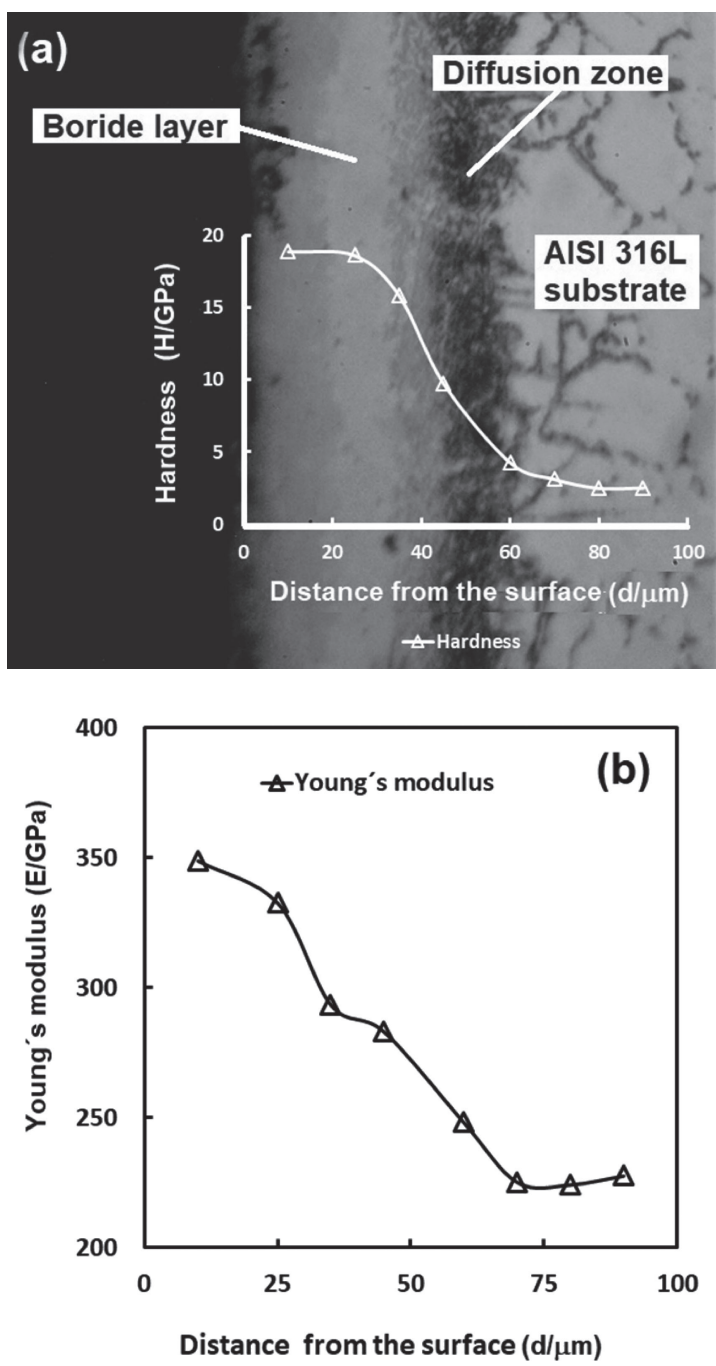

Fig. 4 (a) Hardness profile and (b) Young's modulus as a function of the distance from the surface.

steel. Moreover, during the boriding process $\mathrm{Cr}$ tend to emigrate from the steel to form chromium borides $(\mathrm{CrB}$ and/or $\mathrm{Cr}_{2} \mathrm{~B}$ ). Also, Ni diffuses from the alloy but in smaller proportion, and it is located beneath the layer. ${ }^{28)}$ This behavior of the alloying elements might explain the flat morphology of the borided layers when stainless steel is exposed to boriding. The morphology and the layer thickness were compared with those obtained by Osbek et al. ${ }^{2)}$ and resulted similar in both layer thickness and morphology. Probably the differences in the layer thickness obtained by Osbeck and the present work can be attributed to the differences in the boriding media (slurry salt bath and powder-pack boriding respectively). Some studies have demonstrated that boriding process is more efficient in solid media than that carried out in a slurry salt bath, so that, the layer thickness tends to be also higher at the same material and treatment conditions. ${ }^{28)}$

\subsection{Mechanical characterization}

According to the indentation tests, the hardness was increased from approximately $2.5 \mathrm{GPa}$ at the substrate to about $18.89 \mathrm{GPa}$ at the boride layers. Those hardness values were also in concordance with the three zones of the boride surface (see Fig. 4).
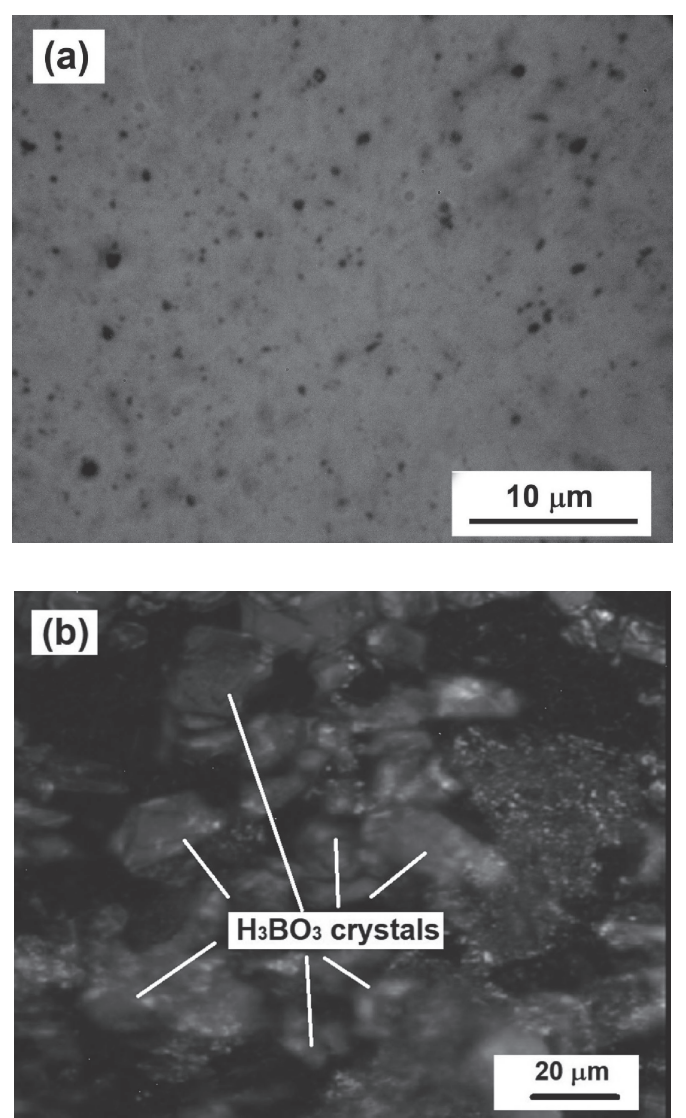

Fig. 5 Surface view of the borided sample (a) before and (b) after SAP showing $\mathrm{H}_{3} \mathrm{BO}_{3}$ crystals.

The highest hardness of the boride layers was directly related with the highest boron content into the layer, ${ }^{20)}$ so that, it is valid to assume that the boride layer can provide enough boron for the formation of a homogenous $\mathrm{H}_{3} \mathrm{BO}_{3}$ film (see Fig. 3(b)).

On the other hand, Young's modulus values obtained at the borided layers were ranged in $348.92 \mathrm{GPa}$, while at the substrate was of $227.78 \mathrm{GPa}$. These results indicate that Young's modulus was also influenced by the boron diffusion since the layers tended to be harder in the near of the surface which indicates that they are less susceptible to plastic deformation. $^{21)}$

\subsection{Boric acid films characterization}

Figure 5 shows a comparison of the surface views of the samples before and after SAP. As can be seen, a homogeneous film of crystals of $\mathrm{H}_{3} \mathrm{BO}_{3}$ was generated during the SAP which was not present before the treatment (Figs. 5(a) and 5(b) respectively). Those film can be assumed to be an $\mathrm{H}_{3} \mathrm{BO}_{3}$ film generated during the SAP.

The chemical nature of the film was demonstrated by Raman spectroscopy analysis by comparing the Raman pattern of the $\mathrm{H}_{3} \mathrm{BO}_{3}$ in natural conditions $\left(879 \mathrm{~cm}^{-1}\right)$ with the surface of the samples exposed to SAP. The Raman spectra of the surface of the samples exposed to SAP revealed the presence of two well-defined bands, where the first of them is approximately at $498 \mathrm{~cm}^{-1}$ and the second one, is approximately at $879 \mathrm{~cm}^{-1}$. The second signal is an exact match of the pure $\mathrm{H}_{3} \mathrm{BO}_{3}$ (Fig. 6). These results were 


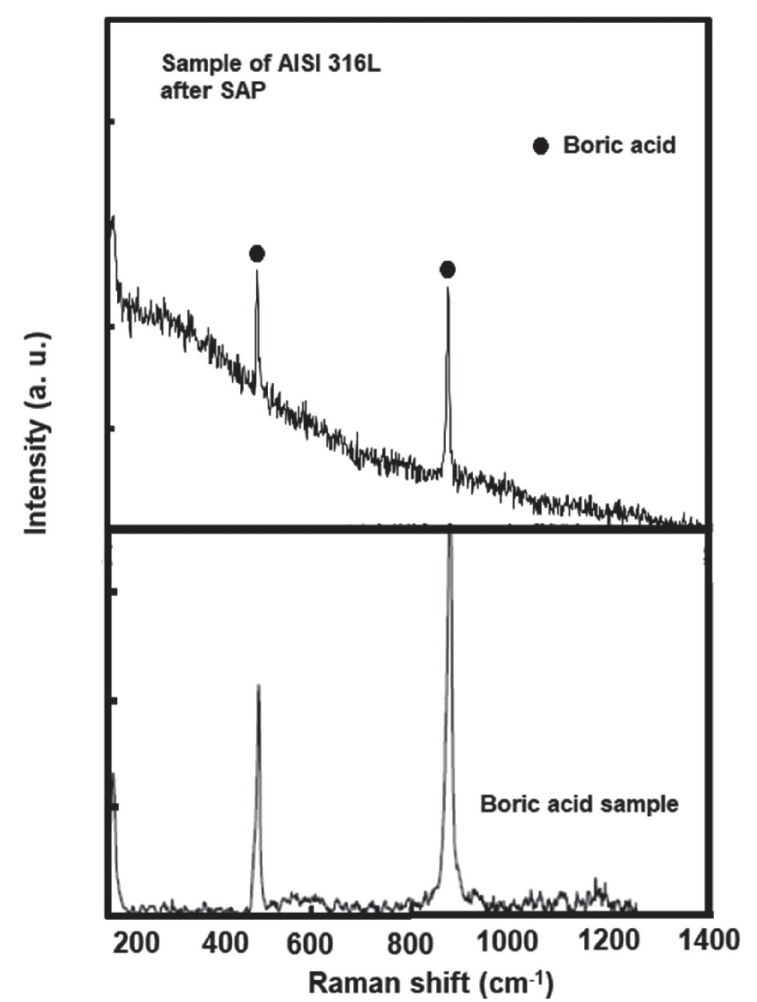

Fig. 6 Raman pattern achieved at the surface of the borided samples after SAP.

concordant with those achieved in previous work with the same steel, ${ }^{14)}$ so it is possible to assume that the surface film is mainly compounded of $\mathrm{H}_{3} \mathrm{BO}_{3}$.

\subsection{Pin on disk tests}

Figure 7 compares the $\mathrm{CoF}$ of the tribological pair WC ball against the samples at the three conditions of treatment, $\mathrm{M} 1, \mathrm{M} 2$, and M3. As can be observed, the CoF was reduced from 0.8 at the surface of the M1 to 0.2 at the M2 samples and to an even lower 0.02 after SAP (M3). Those CoF's values were also concordant to those reported in previous work $^{14)}$ and by Erdemir et al. during the evaluation of the tribological behavior of the naturally occurring $\mathrm{H}_{3} \mathrm{BO}_{3}$ on boron carbide. ${ }^{11)}$ As it can be appreciated in the results, the reduction on the $\mathrm{CoF}$ values even in comparison to those presented by the borided steel is clear, showing the high lubricant capability of the $\mathrm{H}_{3} \mathrm{BO}_{3}$ film. On the other hand, a lower value of $\mathrm{CoF}$ indicates lower values of wear rate, which means that the lifetime of the elements could be increased by applying the SAP. ${ }^{29)}$

In addition, according to Rabinowicz, ${ }^{30)} \mathrm{CoF}$ values ranged from 0.1 to 0.07 are considered as "excellently lubricated surfaces". This condition let to suppose that the samples exposed to SAP can be more apt to face the wear conditions generated in joint prostheses.

The low values of CoF of the samples exposed to SAP (M3) can be attributed to the crystalline structure in a lamellar lattice shape of the $\mathrm{H}_{3} \mathrm{BO}_{3}$, where the atoms in the same layer are closely packed and strongly bonded to each other. However, at the same time, the layers are relatively separated and they are only bonded by weak forces of Van der Walls. ${ }^{13)}$ Moreover, due to that condition, when the $\mathrm{H}_{3} \mathrm{BO}_{3}$ is present

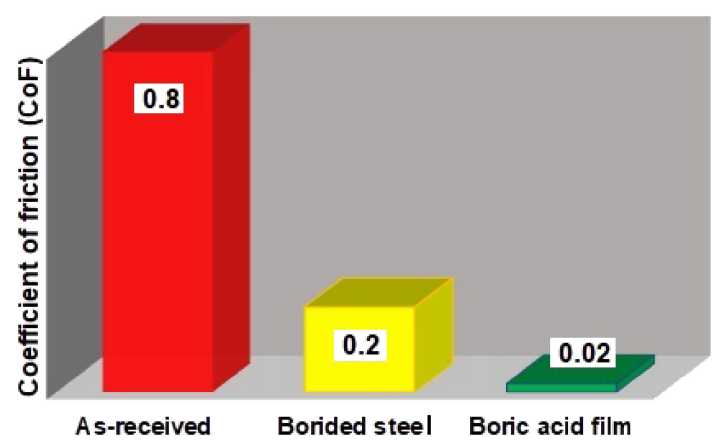

(a)

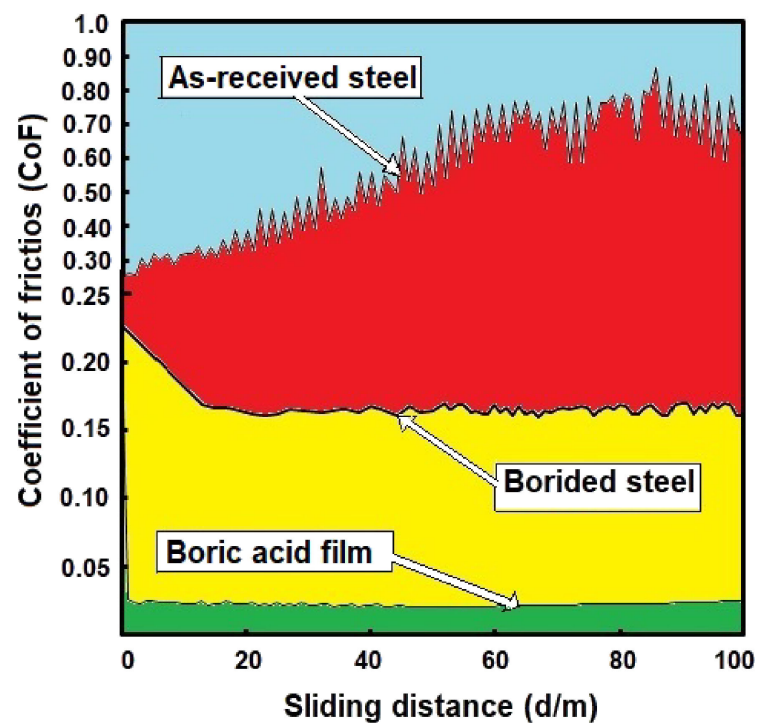

(b)

Fig. 7 Friction coefficient tests of the AISI 316L steel for the different conditions of treatment (Table 2).

between two materials in contact with relative movement each other, the layers tend to align themselves in the direction of the movement with relative ease diminishing the $\mathrm{CoF}$ and consequently wear.

Figure 8 shows the friction trace during the pin-on-disk tests, where it is possible to observe how the $\mathrm{H}_{3} \mathrm{BO}_{3}$ layers are aligned to the movement, and practically there is no debris because of the contact with the WC ball. Likewise, the WC ball (Fig. 8(b)) does not show significant wear highlighting their resistance to wear conditions as the expected at the surface of the joint prostheses.

\subsection{Effect of the cytotoxic and anti-proliferative activity of the $\mathrm{H}_{3} \mathrm{BO}_{3}$ films on the monolayers of MDCK cells}

Although the exceptional wear resistance of the $\mathrm{H}_{3} \mathrm{BO}_{3}$ film, its biocompatibility has not been assessed before. Thus, in the second part of our investigation, we determinate the biocompatibility of the modified materials. We measured the mitochondrial function on the MDCK II cells, widely used given their sensitivity to the toxic effect of different compounds, by the MTT assay. Thus, the cells were incubated in the presence of untreated and treated materials. None of the materials induced significant cytotoxicity on the 

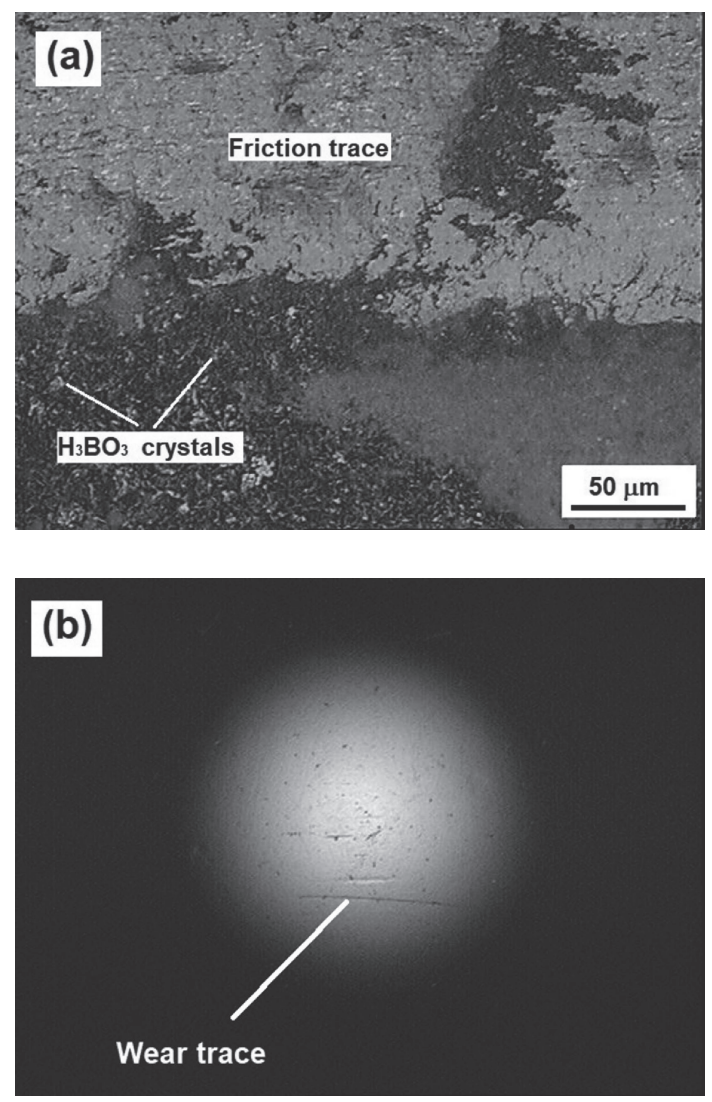

Fig. 8 (a) Scar of the pin on disk test on the M3 sample and (b) Image of the WC ball after the pin-on-disk test.

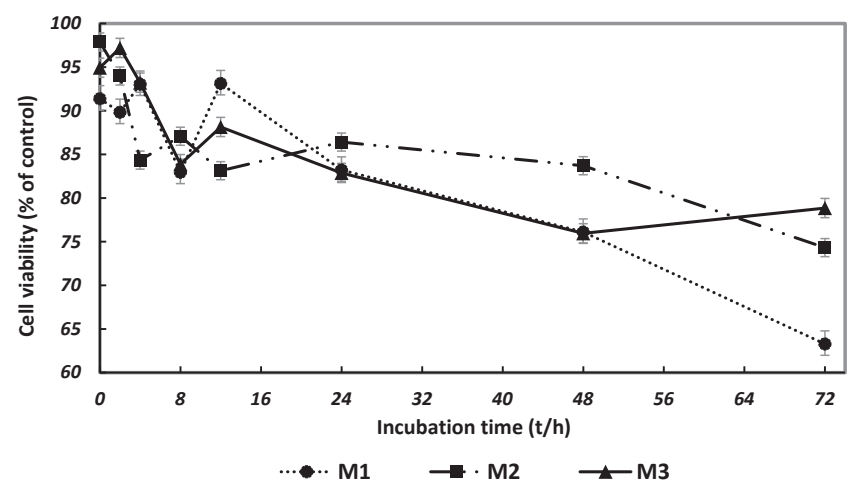

Fig. 9 MTT assays for the samples at the three different conditions of treatment.

MDCK cells which maintained up to $90 \%$ of viability after $24 \mathrm{~h}$ of exposure. When evaluating further times points, 48 and $72 \mathrm{~h}$, a slightly but not significant decrease of viability was seen with the borided and boric acid films. However, the non-treated samples showed a pronounced decrease in viability after $72 \mathrm{~h}$ of exposure as shown in Fig. 9.

It is important to mention that the medium was not changed during the assay which can cause cellular stress, alteration in $\mathrm{pH}$, promote cell aging and the accumulation of toxic compounds released by the cells. Thus, it seems that the boric acid samples help to maintain cellular homeostasis and avoiding apoptosis. It has been reported that boron compounds including boric acid help to reduce cellular oxidative stress by inhibiting the production of reactive oxygen species (ROS), and adjust the $\mathrm{pH}$ functioning as buffers or neutralizing agents. Additionally, they reduce the level of the principal inflammatory mediators such as highsensitivity C-reactive protein (hs-CRP), tumor necrosis factor $\alpha(\mathrm{TNF}-\alpha)$ and interleukin 6 (IL-6). ${ }^{31-34)}$ Interestingly, this cytoprotective effect of the boron derivatives has been reported before. Pure iron cover with different alloys including boron showed a significant decrease in cellular viability at $24 \mathrm{~h}$. However, the cells exposed to boron showed a two-fold recovery in viability at $96 \mathrm{~h}$ confirming the beneficial effect of boron compounds.

\subsubsection{Analysis of the cell death markers expression}

Once it was determined that samples M2 and M3 do not affect mitochondrial function, it was decided to analyze by immunofluorescence the expression of caspases 3 and 9 as an earlier marker of mitochondrial damage and apoptosis.

In Fig. 10(a) it is possible to observe representative images of the kinetics performed during the assay. After $12 \mathrm{~h}$ of direct contact, the M2 samples showed a few numbers of apoptotic cells indicated by the green fluorescence. On the contrary, red and green fluorescence cells were absent during the same period of time with the sample M3. The blue fluorescence represents the nucleus of each cell. Moreover, Fig. 10(b) and (c), shows the fluorescence intensity of Camp9 and -3 measured at different periods of time $(0,4,8,12$ and $24 \mathrm{~h})$.

As it is shown in Fig. 10 the expression of (b) caspase 9 and (c) caspase 3 was the same at the beginning of the experiment $(t=0)$ in all samples condition, but the expression of both caspases was lower in the M3 sample when compared with the M1 and M2 samples. When the cells suffer damage in its mitochondrial membrane, different stimulators like Bax, P53, and TNF launch the proapoptotic signal that releases cytochrome $\mathrm{C}$ in the cytosol and activates the initiator caspase (Casp-9). Once activated, Case-9 can activate the critical effector caspase (Casp-3) leading to cell death by ruining the mitochondrial membrane. ${ }^{35-37)}$ Overexpression of caspase 9 can be observed at $8 \mathrm{~h}$ or earlier times depending on the toxicity of the compounds tested. ${ }^{36)}$ However, this is not the case in the M3 samples, where the expression of both caspases was lower at most of the times points analyzed. Thus, the results demonstrate that the cells did not show a cytotoxic effect in the presence of boric acid films (M3) suggesting that these films might be safe for biomedical applications.

\section{Conclusions}

During the boriding process applied to AISI 316L SS, a compact and homogenous layer of iron borides with flat morphology can be obtained; then followed by SAP a thin surface film of $\mathrm{H}_{3} \mathrm{BO}_{3}$ was formed. Moreover, the $\mathrm{H}_{3} \mathrm{BO}_{3}$ surface film had an excellent self-lubricating surface demonstrated by the extremely low CoF. Additionally, the $\mathrm{H}_{3} \mathrm{BO}_{3}$ surface film not only was biocompatible to the cells, when cytotoxicity was evaluated in vitro but also seemed to have a protective effect against cellular stress. Thus, the extremely low $\mathrm{CoF}$ and high biocompatibility prove that these materials can be used for joint prostheses which are under constant friction condition. Nonetheless, some aspects need to be considered to be further asserted, the inflammatory 
(a)
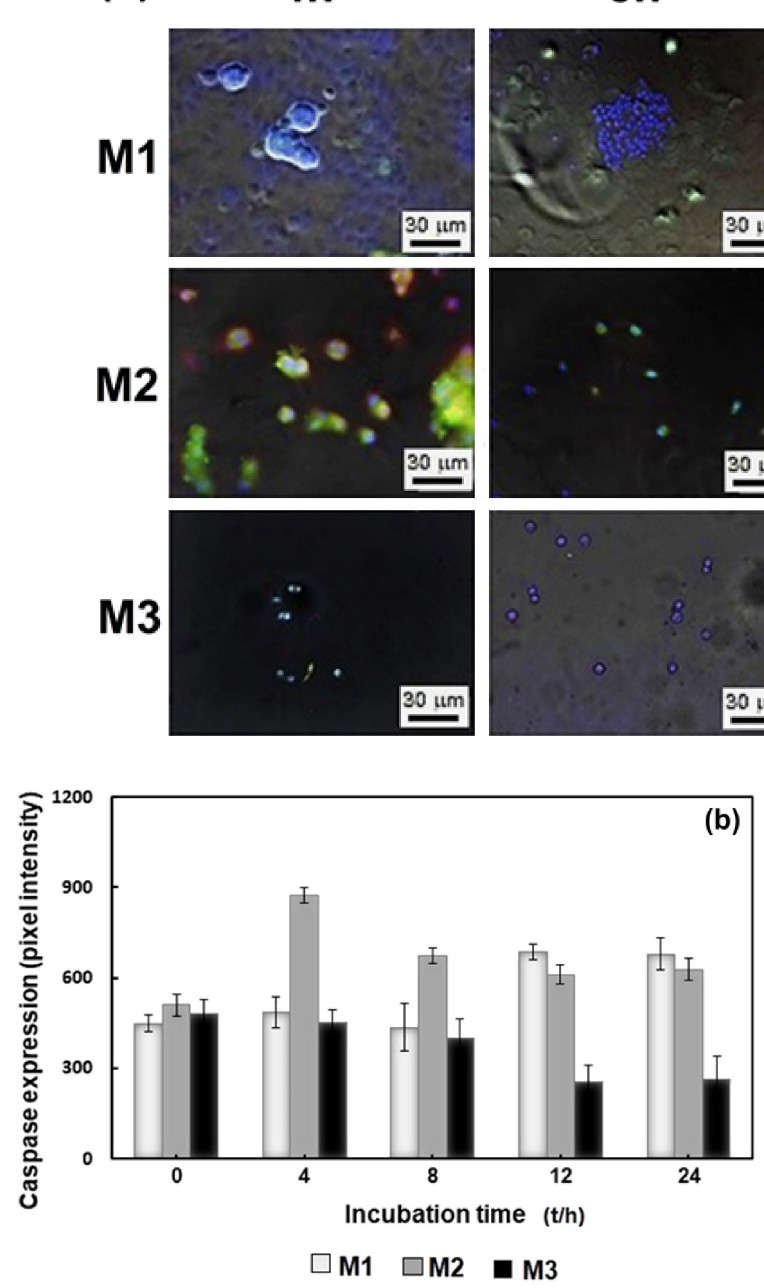

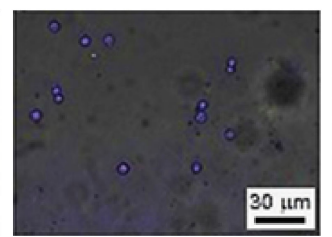

$8 \mathrm{~h}$
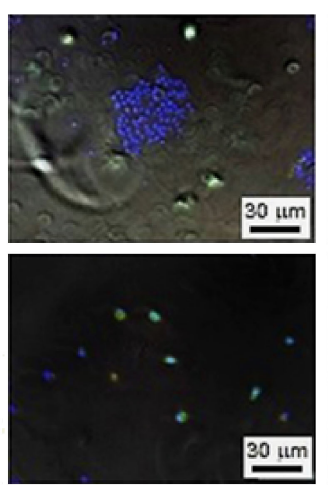

$00 \mathrm{~mm}$
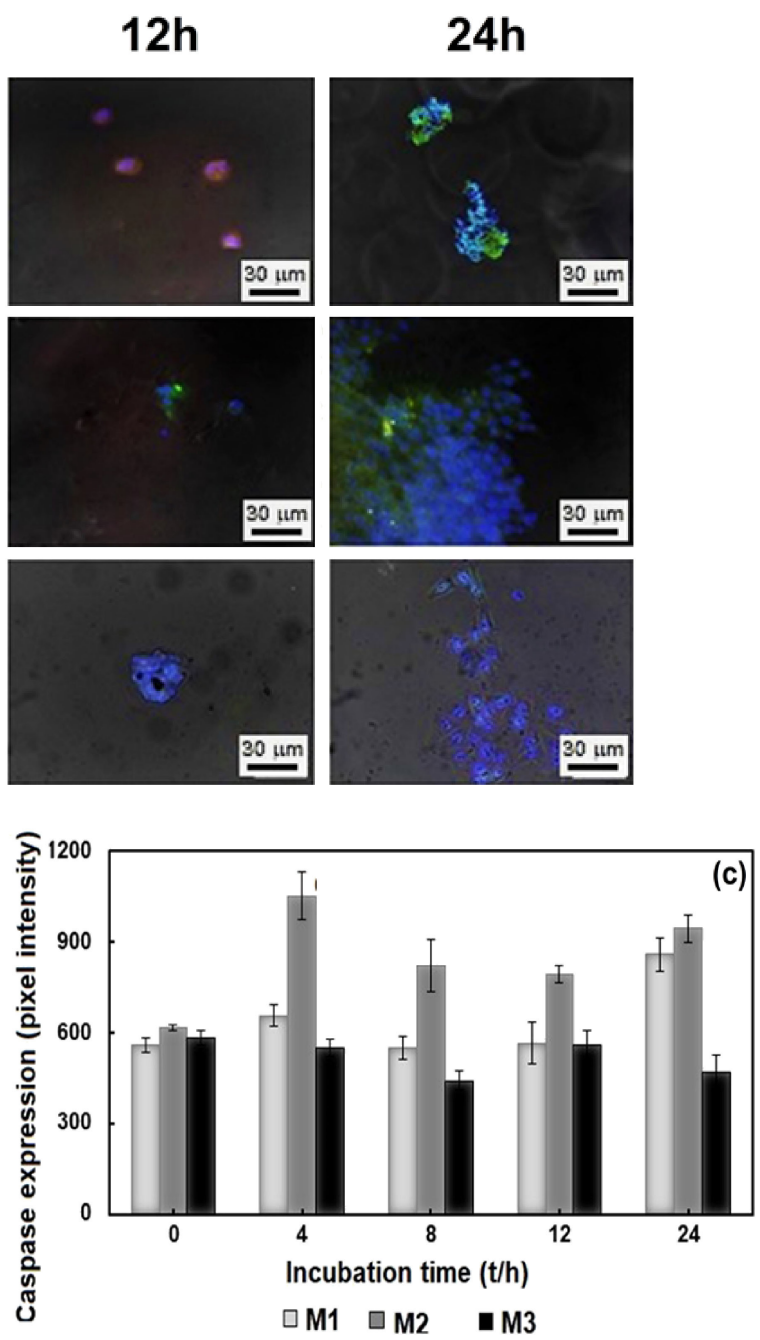

Fig. 10 (a) Representative images of confocal microscopy of caspases expression at different periods of time (4-24h) where green color indicates casp-3 and red casp-9 expression. Fluorescence intensity of caspase-9 (b) and caspase-3 (c) expression in the different samples using MDCK cells. Values represent the mean $( \pm)$ S.D.

capacity of the material and also improve in vitro viability technics to ensure that there is direct cell-material contact, in order to obtain results closer to reality before the in vivo biocompatibility assays.

\section{Acknowledgments}

This work was supported by research Grant 20180815 of Instituto Politécnico Nacional in Mexico. The authors wish to thank the Center of Nanosciences and Micro-Nano Technologies of the Instituto Politécnico Nacional for their cooperation. Additionally, they would like to thank the Instituto Tecnológico de Estudios Superiores Monterrey in Mexico for its collaboration in the development of this work.

\section{REFERENCES}

1) I. Gurappa: Surf. Coat. Technol. 161 (2002) 70-78.

2) I. Ozbek, B.A. Konduk, C. Bindal and A.H. Ucisik: Vacuum 65 (2002) 521-525.

3) V. Vincent Carsi, M.J. Sangüesa Nebot, J.J. Terradez Raro and C. Valverde Mordt: Rev. Esp. Cir. Osteoart 31 (1996) 59-61.

4) B. Seral García, T. Castiella Muruzabal, L. Paniagua Royo, J. Segura
Mata and E. Seral Iñigo: Rev. Esp. Cir. Osteoart. 31 (1996) 171-176. 5) E. Hernández-Sánchez, Y.M. Domínguez-Galicia, C. Orozco-Álvarez, R. Carrera-Espinoza, H. Herrera-Hernández and J.C. Velázquez: Adv. Mater. Sci. Eng. 2014 (2014) 1-9.

6) O. Ozdemir, M.A. Omar, M. Usta, S. Zeytin, C. Bindal and A.H. Ucisik: Vacuum 83 (2008) 175-179.

7) D. Berman, A. Erdemir and A.V. Sumant: Mater. Today 17(1) (2014) 31-42.

8) L. Sterle, M. Kalin and F. Pušavec: Procedia CIRP 77 (2018) 401-404.

9) M.A. Makhesana and K.M. Patel: Ind. Lubr. Tribol. 68 (2016) 591596.

10) J.C. Spear, B.W. Ewers and J.D. Batteas: Nano Today 10 (2015) 301314.

11) A. Erdemir, C. Bindal, C. Zuiker and E. Savrun: Surf. Coat. Technol. 86-87 (1996) 507-510.

12) P. Deshmukh, M. Lovell, W. Gregory Sawyer and A. Mobley: Wear 260 (2006) 1295-1304.

13) A. Erdemir and O.L. Eryilmaz: Superlubricity in Diamond-Like Carbon Films, in Superlubricity, (Elsevier B.V., 2007) Chapter 16.

14) E. Hernández Sanchez, H. Herrera-Hernández, A. Chino-Ulloa, J.C. Velázquez, R. Velázquez-Mancilla and R. Carrera-Espinoza: Adv. Mater. Sci. Eng. 2015 (2015) 1-9.

15) J.E. Perez, M.F. Contreras, E. Vilanova, L.P. Felix, M.B. Margineanu, G. Luongo, A.E. Porter, I.E. Dunlop, T. Ravasi and J. Kosel: Nanotoxicology 10 (2016) 871-880.

16) B. Ankamwar, T.C. Lai, J.H. Huang, R.S. Liu, M. Hsiao, C.H. Chen and Y.K. Hwu: Nanotechnology 21 (2010) 075102. 
17) J.L. West and N.J. Halas: Annu. Rev. Biomed. Eng. 5 (2003) 285-292.

18) K.K. Jain: Technol Cancer Res Treat. 4 (2005) 407-416.

19) M. Graf von Matuschka: Boronizing, 1st ed., (Carl Hanser, Munich, Germany, 1980).

20) G. Rodríguez-Castro, I. Campos-Silva, E. Chávez-Gutiérrez, J. Martínez-Trinidad, E. Hernández-Sánchez and A. Torres-Hernández: Surf. Coat. Technol. 215 (2013) 291-299.

21) E. Hernández-Sánchez, G. Rodríguez-Castro, A. Meneses-Amador, D. Bravo Bárcenas, H. Martínez-Gutiérrez, M. Romero-Romo, I. CamposSilva and I. Arzate-Vazquez: Surf. Coat. Technol. 237 (2013) 292-298.

22) J.C. Stockert, R.W. Horobin, L.L. Colombo and A. Blázquez-Castro Acta Histochem. 120 (2018) 159-167.

23) G. Fotakis and J.A. Timbrell: Toxicol. Lett. 160 (2006) 171-177.

24) W.C. Oliver and G.M. Pharr: J. Mat. Res. 7 (1992) 1564-1583.

25) A.C. Fischer-Cripps: Introduction to Contact Mechanics: Mechanical Engineering Series, (Springer-Verlag, New York, 2006).

26) International Organization for Standardization: Biological evaluation of medical devices - ISO 10993, Part 5: Tests for in vitro cytotoxicity, (Geneva, Switzerland, 2009).

27) G. Palombarini and M. Carbucicchio: J. Mater. Sci. Lett. 3 (1984) 791794.

28) I. Campos-Silva, M. Ortiz-Domínguez, O. Bravo-Bárcenas, M.A. Doñu-Ruiz, D. Bravo-Bárcenas, C. Tapia-Quintero and M.Y. Jiménez-
Reyes: Surf. Coat. Technol. 205 (2010) 403-412.

29) E. Hernández-Sánchez, J.C. Velázquez, J.L. Castrejón-Flores, A. Chino-Ulloa, I.P. Torres Avila, R. Carrera-Espinoza, J.A. YescasHernández and C. Orozco-Álvarez: Mater. Trans. 60 (2019) 156-164.

30) E. Rabinowicz: Friction, and Wear Materials, (John Wiley \& Sons, Inc., New York, 1995).

31) T.L. Litovitz, W. Klein-Schwartz, G.M. Oderda and B.F. Shmitz: Am. J. Emerg. Med. 6 (1988) 209-213.

32) F. Karabag Coban, R. Liman, İ. Hakki Ciğerci, S. Ince, O. Hazman and M. Fatih Bozkurt: Fresenius Environ. Bull. 24(11-B) (2015) 40594066.

33) U. Acaroz, S. Ince, D. Arslan-Acaroz, Z. Gurler, I. Kucukkurt, H. Demirel, H. Ozancan Arslan, N. Varol and K. Zhu: Food Chem. Toxicol. 118 (2018) 745-752.

34) K.H. Beyer, W.F. Bergfeld, W.O. Berndt, R.K. Boutwell, W.W. Carlton, D.K. Hoffmann and A.L. Schroeter: J. Am. College Toxicol. 2(7), (1983) 77-87.

35) G. Kroemer, B. Dallaporta and M. Resche-Rigon: Annu. Rev. Physiol. 60 (1998) 619-642.

36) M. El Khachibi, M. El Karroumi, S. Eddine Ayoubi, N. El Kadmiri and S. Nadifi: Gene Rep. 10 (2018) 47-53.

37) P.A. Trzaskowska, A. Kuźmińska, B. Butruk-Raszeja, E. Rybak and T. Ciach: Colloids Surf. B: Biointerfaces 167 (2018) 499-508. 